\title{
Gobernar, (es) capturar y colonizar: tercer ciclo de neoliberalización en la política agraria argentina*
}

\author{
Recibido: 27 de mayo de 2019 - Aprobado: 25 de julio de 2019 \\ https://doi.org/10.22395/seec.v22n52a4
}

Ariel García**

\section{RESUMEN}

En este artículo se considera que los ciclos de neoliberalización deben enmarcarse en el estudio de la articulación dinámica y polifacética entre agentes económicos y dispositivos estatales. El objetivo es analizar las características del tercer ciclo de neoliberalización (2015-2019) en la política agraria argentina en relación a su desestructuración y reestructuración excluyente. A partir de un enfoque de triangulación metodológica, se presenta como referente empírico la dinámica de la política agraria instrumentada desde dos entidades gubernamentales: el Ministerio de Agroindustria (degradado a Secretaría en 2018) y el Instituto Nacional de Tecnología Agropecuaria (INTA). Específicamente, se identifican procesos de captura y colonización de la dirección de ambas entidades por parte de organizaciones de interés que responden a elites económicas del sector agroindustrial.

\section{PALABRAS CLAVE:}

Captura del Estado; gobierno; neoliberalización; política agraria.

\section{CLASIFICACIÓN JEL:}

H3; F5; H53; H68; 013

\section{CONTENIDO:}

Introducción; 1. Desmontar el gobierno y capturar el Estado; 2. Políticas agrarias: desestructuración y reestructuración excluyente; 3 . La puerta giratoria de las usinas de pensamiento: colonización y desmonte de las políticas estatales; 4. Conclusiones; Bibliografía.

Esta investigación se inscribe en el proyecto PICT 1026/2013 Experiencias productivas asociativas, políticas públicas y territorio. Propuesta para un modelo de desarrollo regional con empleo e inclusión social, Secyt, Argentina.

* Geógrafo, UBA, Buenos Aires, Argentina (UBA). Magíster en Estudios Sociales Agrarios, Flacso, Buenos Aires, Argentina. Doctor en Geografía, UBA, Buenos Aires, Argentina. Investigador adjunto del Centro de Estudios Urbanos y Regionales (CEUR-Conicet), Buenos Aires, Argentina. Profesor de Economía Política (FCS-UBA) y Geografía Económica (FFyL-UBA). Correo electrónico: arielgarcia@conicet.gov.ar 


\title{
TO GOVERN, (IS) TO CAPTURE AND COLONIZE: THIRD CYCLE OF NEOLIBERALIZATION IN THE ARGENTINIAN AGRARIAN POLICY
}

\begin{abstract}
This article considers that the cycles of neoliberalization must be framed in the study of the dynamic and multifaceted articulation between economic agents and estate dispositifs. The goal is to analyze the characteristics of the third cycle of neoliberalization (2015-2019) in the Argentinian agrarian policies concerning its exclusive de-structuring and restructuring. Parting from a methodological triangulation approach the dynamics of the agrarian policy is presented from two governing entities: the Ministry of Agroindustry (degraded to Secretariat in 2018) and the National Institute for Agricultural Technology (INTA in Spanish). Specifically, the processes of capture and colonizing in the directing of both entities by interested organizations that respond to economic elites from the agricultural sector.
\end{abstract}

KEYWORDS:

State capture; government; neoliberalization; agricultural policy.

JEL CODE:

$\mathrm{H} 3 ; \mathrm{F} 5 ; \mathrm{H} 53 ; \mathrm{H} 68 ; 013$

\section{CONTENTS:}

Introduction; 1. Dismantle the government and capture the state; 2. Agricultural policies: exclusive de-structuring and restructuring; 3 . The rotating gate of thinking plants: colonization and dismantle of the state policies; 4. Conclusions; Bibliography.

\section{GOVERNAR，(É) CAPTURAR E COLONIZAR: TERCEIRO CICLO DE NEOLIBERALIZAÇÃO NA POLÍTICA AGRÁRIA ARGENTINA}

\section{RESUMO}

Neste artigo, considera-se que os ciclos de neoliberalização devem ser delimitados no estudo da articulação dinâmica e multifacetada entre agentes econômicos e dispositivos estatais. O objetivo deste estudo é analisar as características do terceiro ciclo de neoliberalização (2015-2019) na política agrária argentina quanto à sua desestruturação e reestruturação excludente. A partir de uma abordagem de triangulação metodológica, é apresentada como referente empírico a dinâmica da política agrária instrumentada sob duas entidades governamentais: o Ministério da Agroindústria (reduzido à Secretaria em 2018) e o Instituto Nacional de Tecnologia Agropecuária (INTA). Em específico, são identificados processos de captura e colonização da direção de ambas as entidades por parte de organizações de interesse que respondem a elites econômicas do setor agroindustrial.

\section{PALAVRAS-CHAVE:}

Captura do Estado; governo; neoliberalização; política agrária.

\section{CLASSIFICAÇÃO JEL:}

$\mathrm{H} 3 ; \mathrm{F} 5 ; \mathrm{H} 53 ; \mathrm{H} 68 ; 013$

\section{CONTEÚDO:}

Introdução; 1. Desestruturar o governo e capturar o Estado; 2. Políticas agrárias: desestruturação e reestruturação excludente; 3 . A porta giratória das usinas de pensamento: colonização e desmonte das políticas estatais; 4. Conclusões; Bibliografia. 


\section{INTRODUCCIÓN}

En Argentina, los ciclos de neoliberalización ${ }^{1}$ se registran con significativa persistencia desde la década de 1970. Al menos tres lapsos fueron emprendidos por las máximas autoridades nacionales: dictadura cívico-militar de 1976 a 1983, los gobiernos de Carlos Menem y Fernando de la Rúa de 1989 a 2001 y el de Mauricio Macri, desde 2015.

La investigación parte por interrogarse ¿cómo se define el campo de acción de los sujetos sociales en un contexto de gobierno neoliberal?, ¿qué sucede cuando una significativa porción de los principales agentes económicos que debieran ser regulados pasan a ser reguladores?, ¿qué tipo de Estado conciben los agentes económicos a partir de sus actos y disposiciones una vez devenidos funcionarios estatales?, ¿cómo se producen procesos de captura de políticas agrarias en términos de los cambios en su orientación?

El objetivo del artículo es analizar las características del tercer ciclo de neoliberalización (2015-2019) en la política agraria argentina en relación a su desestructuración y reestructuración excluyente. Para ello, se presenta como referente empírico la dinámica de la política agraria instrumentada desde dos entidades gubernamentales: el Ministerio de Agroindustria (degradado a Secretaría en 2018) y el Instituto Nacional de Tecnología Agropecuaria (INTA), a partir de la captura y colonización de su dirección por parte de organizaciones de interés que responden a elites económicas del sector.

La investigación se plantea desde un enfoque de triangulación metodológica que recurre a fuentes de información primaria -entrevistas semiestructuradas a funcionarios y a técnicos agropecuarios de INTA- y secundaria -bibliografía académica, informes públicos y periodísticos-.

Por último, la exposición se organiza en cuatro apartados. Tras la introducción, se plantea el problema a partir de exponer el estado de la situación y el marco teórico. En el segundo apartado, se identifica los procesos de desestructuración y reestructuración excluyente a la que asisten las políticas agrarias durante el lapso bajo estudio. En el tercero, se exponen procesos de colonización por parte de organizaciones de interés o por representantes sectoriales del sector privado. Por último, se presentan las conclusiones.

Con ciclos de neoliberalización, se refiere a definiciones de políticas estatales orientadas a la privatización, desfinanciamiento, tercerización, desregulación y focalización. Para un análisis en torno a las variedades del neoliberalismo en América Latina, consultar Maillet (2013) y Fernández (2016). 


\section{DESMONTAR EL GOBIERNO Y CAPTURAR EL ESTADO}

Este apartado consta de dos acápites, se exponen: a) los antecedentes contextuales del lapso 2015-2019 y b) los conceptos a partir de los cuales se aborda el tercer ciclo de neoliberalización en la política agraria argentina.

\subsection{Contexto en el periodo 2015-2019}

Durante el lapso abordado pueden identificarse cinco dimensiones significativas para la problemática de esta investigación. En primer término, la reforma del Estado no aparece tematizada al estilo de lo acaecido durante el apogeo del Consenso de Washington, que postulaba bajo aquel rótulo la privatización, fusión, tercerización o disolución de entes y empresas estatales. Sin embargo, el lapso indagado puede dividirse en dos bienios. Durante 2015-2017, la reforma del Estado es pragmáticamente inducida y dilemáticamente impuesta en dirección a desmontar de forma selectiva la estructura de derechos sociales y a desregular los movimientos de capital. En ese bienio se desmonta la protección en el canal financiero, incentivando la valorización financiera mediante el mecanismo de carry trade a través de tasas altas en la moneda nacional y valor retrasado del dólar - proceso ralentizado desde 2018 tras la devaluación de aquella en más de 100 \%-. Mientras tanto, en el bienio 2017-2019 el ritmo del desmonte estatal se torna vertiginoso y se aleja del pragmatismo selectivo tras la suscripción del acuerdo stand by con el Fondo Monetario Internacional (FMI).

En segundo lugar, durante el cuatrienio 2015-2019 la institucionalidad concebida por el Gobierno Nacional se mantiene y consiste en: a) nueva contratación de servicios y creación de unidades estatales dirigidos a retribuir clientelarmente a los segmentos sociales integrantes del proyecto político (Cao, Laguado Duca y Rey, 2018, p. 141); b) intentos infructuosos de implementar programas de participación público privada (PPP) y c) búsqueda de coordinación fiscal-financiera entre el orden federal y subnacional (García Delgado, 2017, pp. 95-96). Esta institucionalidad se centra en brindar privilegios a cada fracción del bloque de poder que sostiene la alianza gobernante -complejos agroexportador, energético y financiero- vía reducción de impuestos a los bienes personales, dolarización de tarifas de servicios públicos y combustibles, mediación en las paritarias sectoriales a favor del capital, etc. Esta institucionalidad se forjó desatendiendo la coherencia de las definiciones o sus consecuencias en la estructura político-institucional y económica (Aronskind, citado por Cao, Laguado Duca y Rey, 2018, p. 141).

En tercer término, el Gobierno Nacional se deslinda de la responsabilidad de asegurar condiciones básicas para sostener el tejido productivo, sobre todo el industrial, afectado por el fomento a las importaciones, la retracción del mercado 
interno producto de la pérdida del poder adquisitivo, la aludida dolarización de las tarifas de los servicios públicos y el incremento de las tasas de interés.

En cuarto lugar, el elenco gubernamental que asumió en diciembre de 2015 posee un rasgo cualitativo y cuantitativo distintivo de las administraciones que lo precedieron. Específicamente, el riesgo de conflicto de interés -eufemismo de corrupción-y captura del Estado radica en el peso de casos directos de puerta giratoria, movimiento que evidencia el límite difuso y dinámico entre poder económico y político o la colonización del primero sobre el segundo. A partir de un análisis de Canelo, Castellani y Gentile (2018, pp. 124-125), se halla que, del gabinete constituido en aquella fecha, un $22 \%$ de quienes lo integraban detentaban un cargo privado al ser designados (78 sobre 351 cargos). Según las autoras, estas designaciones serían irrealizables de aplicarse las recomendaciones internacionales vigentes o bien la legislación argentina previa a la reforma de 2001 (mediante el Decreto 862/2001) de la Ley de Ética Pública². Canelo, Castellani y Gentile (2018, p. 125) encuentran que, de los 78 casos citados, 55 ocupaban los cargos gerenciales más altos en sus firmas privadas. Asimismo, que 62 \% de los casos se integraron a siete ministerios nacionales (del área política y económica). En el caso del Ministerio de Agroindustria ${ }^{3}$, 27 \% de los funcionarios designados poseían antecedentes de alta dirección en el sector privado, se encontraron cinco casos directos de puerta giratoria.

Los recién aludidos casos de puerta giratoria desde el sector privado al público suelen ser justificados desde el elenco gubernamental a través de la enunciación de las características que se supone reunirían los empresarios exitosos. Este nuevo tipo ideal de gerentes estatales se asocia a su hipotética aptitud para dedicarse a cualquier actividad. Por detrás de este parecer, se ubica un juicio que sugiere que la capacidad de lograr altas ganancias es la prueba más exigente a la que puede someterse un profesional (Cao, Laguado Duca y Rey, 2018, p. 146). En el caso específico del empresario agropecuario, Gras y Hernández (2016, pp. 111-112) analizan que una de las dirigencias más afines a esta idea-fuerza es la Asociación Argentina de Consorcios Regionales de Experimentación Agrícola (AACREA). Esa dirigencia suma a lo anterior un elemento moral de base cristiana, que asocia la inversión en tecnología con la posibilidad de concebir un proyecto modernizador traducido en

\footnotetext{
2 Sancionada en 1999, preveía que los funcionarios que hubieran participado de privatizaciones tendrían vedada su actuación en entes reguladores de esas empresas durante tres años posteriores a la última adjudicación en la que hayan participado.

3 Como tal, Agroindustria ha detentado nivel ministerial desde octubre de 2009 hasta septiembre de 2018. La degradación de la cartera al rango de secretaría ha implicado una vuelta a la preeminencia de definiciones de política económica para el sector, característica en experiencias previas de desmonte estatal.
} 
el incremento del rendimiento de la tierra que provea al bien común, a la grandeza de la nación.

En quinto término, en el lapso iniciado en 2015, el tipo ideal de administrador estatal aparece como alguien incorruptible con el dinero público porque su condición de clase le aseguraría su futuro. Asimismo, resulta recurrente una prédica antiestatista y una evaluación negativa sobre la histórica eficiencia estatal como justificación para el desmonte de sus funciones. Esta valoración se suma a una visión presuntamente tecnocrática en cabeza del entonces Ministerio de Modernización, que implementó una racionalización para justificar la cesantía de personal en diversas áreas de la administración nacional, amparándose en el tecnicismo del Plan de dotación óptima ${ }^{4}$. Paradójicamente, y para el caso de los agronegocios, el gran empresariado suele desestimar y enfrentarse a cualquier forma de imposición fiscal para las ganancias extraordinarias que se pueden obtener de la escala, fertilidad y ubicación privilegiada de la pampa húmeda. Una evidencia de esto ha sido el conflicto desatado en 2008 entre las patronales agropecuarias, los adoptantes de tecnología y el Gobierno Nacional por la renta agraria. ${ }^{5}$

La participación política de algunos de los miembros de Aacrea en la cartera de Agroindustria implicó desavenencias en la estructura de la organización, debido al juicio negativo que usualmente mantienen sobre la política en general y el Estado en particular. Esta Asociación posee una significativa inserción en la agenda pública agroindustrial, sobre todo la vinculada al agronegocio. Esta imbricación se ha materializado en la invitación de técnicos del INTA a reuniones técnicas y en la contratación de profesionales para estudiar temas diversos. No obstante, entre los miembros de Aacrea para quienes la participación en la política estatal obtuvo prédica, la estrategia de colonización en distintos espacios institucionales ha implicado una actuación contraria a los sujetos subalternos. Esta colonización se hizo efectiva en la presidencia del Servicio Nacional de Sanidad y Calidad Agroalimentaria (Senasa), en el exministerio -en su secretaría, en su jefatura de gabinete, en una

${ }_{4}$ En septiembre de 2017, desde el Ministerio de Modernización, se consideraba que 19.119 trabajadores del Estado Nacional sobre una planta de 129.606 excedían la dotación óptima y se estableció un congelamiento de ingresos hasta 2020, buscando su reducción vía "jubilaciones anticipadas, retiros voluntarios, cese de contratos (...) y eliminación de "exceso" de personal en algunas dependencias oficiales" (Visión Liberal, 2018). Esta evaluación es paralela a la contratación de funcionarios de procedencia partidaria -3.400 según la fuente recién apuntada-, con salarios usualmente superiores a los que se dejan de devengar por las cesantías planificadas en 21 ministerios, 87 secretarías de Estado, 207 subsecretarías de Estado y 687 direcciones nacionales (La Nación, 2017b).

5 En marzo de 2008, durante el primer gobierno de Cristina Kirchner, el Ministerio de Economía intentó implementar un sistema de retenciones móviles a las exportaciones en un contexto de alza sostenida de los precios de los commodities y de la soja en particular. Esta medida apuntaba a capturar parte de las rentas extraordinarias obtenidas por el sector-distribuyéndolas a otras fracciones sociales-y desarrollar una política antiinflacionaria al desacoplar los precios externos de los internos (Armengol, 2015, p. 4). 
de las seis subsecretarías, quedando las restantes para representantes de cámaras empresariales- y en el INTA -su presidencia, vicepresidencia y una vocalía de un total de ocho que integran el Consejo Directivo, sumada a otra cuyo representante es elegido por las autoridades del exministerio-. En el marco de este instituto, dicho Consejo se ha mostrado alineado con la reorientación hacia los sectores agrarios capitalizados y contrario a la actuación de la Coordinación Nacional de Transferencia y Extensión (CNTE) -enfocada en la pequeña y mediana producción así como responsable de la articulación con el exministerio en la implementación operativa del cambio rural y con el Ministerio de Desarrollo Social en torno al programa Prohuerta-y del Cipaf -(Centro de Investigación y Desarrollo Tecnológico para la Pequeña Agricultura Familiar), que cuenta con cinco centros regionales-(Funcionario INTA, 2019b; 2019d). Incluso, la aludida colonización puede observarse mediante la instalación de la incertidumbre laboral, quitando el área de Sumarios Administrativos $^{6}$ de la órbita del Director Nacional, electo por el Consejo Directivo de la entidad durante el final de la presidencia de Cristina Kirchner con un solo voto en contra: el de Aacrea.

\subsection{Gobierno, captura y neoliberalización}

La definición enciclopédica de gobierno refiere al órgano superior del poder ejecutivo de un Estado o de una comunidad política (RAE, 2019). Desde el enfoque aquí adoptado, gobernar implica trascender las formas legítimamente constituidas de sujeción política o económica, incluyendo modalidades de acción -más o menos consideradas y calculadas-, orientadas a actuar sobre las posibilidades de acción de los otros (Foucault, 2001, pp. 253-254). Por lo anterior, según este autor, el efecto de relacionamiento propio del poder no se hallaría en el campo de la violencia o de la unión voluntaria sino en los modos de acción del gobierno; modos no necesariamente jurídicos. De allí que gobernar también sea estructurar el campo de acción de los otros.

Lo que aquí se denomina desmonte del Estado puede comprenderse como una forma particular de estructurar desde el gobierno formalmente instituido el campo de acción de los sujetos sociales. Este campo de acción adquiere características específicas en la tercera generación de reforma del Estado de Argentina, iniciada en la última dictadura cívico-militar (1976-1983) y profundizada durante el período de convertibilidad peso-dólar (1991-2001) desde una adaptación particular del

${ }_{6}$ En el Estado nacional los sumarios se triplicaron de 707 (2015) a 2.165 (2017), siendo el INTA la quinta unidad administrativa en cantidad (La Nación, 2017a). Esta situación abre interrogantes en torno a este medio como disciplinador de los funcionarios públicos. 
enfoque neoliberal que afectó el funcionamiento de los Estados occidentales desde la década de 1970.

Precisamente, Ross Schneider y Karcher (2012, p. 20) indagan el funcionamiento de los Estados occidentales a partir del análisis de la relación estrecha entre gobiernos y grandes empresas. Consideran a autores que estudiaron la temática como Schvarzer y Castellani, para referirse con complejo económico Estado-empresa al conjunto de corporaciones privadas que extraen cuasirrentas usufructuando sus vínculos con el Estado. Asimismo, describen la persistencia dinámica de este complejo a través de las mudanzas del régimen de acumulación en Argentina desde mediados de la década de 1960. En el contexto descripto, el vínculo entre regulación y agentes económicos suele ser dinámico y determina las condiciones de posibilidad del complejo económico Estado-empresa. Esta relación puede derivar en lo que cierta literatura reconoce como captura del ente regulador; en la que el regulador y el regulado, a través del cabildeo, el soborno, la prebenda o la financiación de campañas electorales posibilitan que las normas sean diseñadas para favorecer a estos últimos (Buchanan y Brennan, 1985 y Stigler, 1971) citados por Romero Alvarado (2015, p. 49).

Diversos estudios abordan la influencia neoliberal en las políticas estatales para el caso argentino y latinoamericano. En particular, se interrogan en torno a la dificultad de consecución de una autonomía estatal que obedecería a dos factores. Por un lado, a la reconstrucción sigilosa del proyecto neoliberal en el seno de iniciativas neodesarrollistas ${ }^{7}$ a partir del control de los principales instrumentos de política económica temporalmente situados entre 2002 y 2015, así como por dispositivos simbólico-ideológicos de gobierno que neutralizan cualquier intento de desafiar el patrón de acumulación persistente. Por el otro, a la convivencia de aquel proyecto reformulado con una reedición de las debilidades históricas de dichos intentos -básicamente, desequilibrio en las cuentas externas ante los intentos de reindustrialización- - (Fernández, 2016, p. 26). De esta manera, frente al neoliberalismo ofensivo dirigido a alinear la intervención estatal hacia estrategias desposesivas y de desmonte (privatizaciones, desregulaciones, tercerizaciones) prevaleciente durante el decenio de 1990, las experiencias neodesarrollistas de la década siguiente terminan siendo condicionadas por un neoliberalismo consensual e inclusivista. Esta dinámica limita los espacios de intervención a procesos de redistribución de ingresos sin desafiar el gobierno del régimen de acumulación por parte de agentes económicos que actúan como terminales de redes económicas globales.

Para una definición, véase, Varesi (2016). 
Por lo hasta aquí expuesto, la sigilosa reconstrucción del proyecto neoliberal en sus dos formas básicas y complementarias -el control de instrumentos y dispositivos simbólicos-ideológicos asociados al requisito de horizontalidad de los mismos- limita (captura en los términos aquí asumidos) los grados de autonomía burocrática debido a que implica enraizamientos nocivos para el despliegue y logro de instrumentos institucionales que propendan a la industrialización vía agregado de valor en origen. Como resultado de esta dinámica, traducida en la restricción de divisas (balanza comercial deficitaria), se generan condiciones para el regreso del neoliberalismo en su fase ofensiva. En esta fase se registran procesos de desposesión de instrumentos estatales, caracterizados por el desfinanciamiento de dispositivos públicos, su tercerización o discontinuidad en favor de empresas privadas (Ghibaudi, Lavarello y García, 2018).

No obstante, también puede ocurrir que agentes económicos interesados asuman y defiendan sus intereses sin intermediación, cuando son quienes integran el mismo gobierno, aspecto que constituye casos de puerta giratoria. En Occidente resultan habituales estos casos e incluso pueden pensarse como un modus operandi en distintos sistemas políticos. En la experiencia latinoamericana, Ross Schneider (2010) citado por de Anchorena (2018, p. 187) evidencia la carencia de vínculos formales y orgánicos con partidos políticos que integren empresarios, debido a que estos resultan infrecuentes en el subcontinente. Tal como lo demostró Basualdo (2011) para el caso argentino, las elites económicas se yuxtaponen con las gubernamentales. Ross Schneider (2010) citado por De Anchorena (2018, p. 187) considera que la alta estratificación socioeconómica materializada en vínculos familiares, la asistencia a determinadas universidades, así como la concentración geográfica en las capitales posibilitan la conformación de ámbitos de pertenencia, de redes de elites, incluyendo las asociaciones de interés corporativo y de parentesco.

En suma, la reconstrucción del proyecto neoliberal en sus dos formas básicas y complementarias -el control de instrumentos y dispositivos simbólicos-ideológicos asociados al requisito de horizontalidad de los mismos- limitaría los grados de autonomía burocrática. A su vez, estos grados resultan restringidos por el tipo de vínculos que se construyen entre regulación y agentes, lo que determina las condiciones de posibilidad del complejo económico Estado-empresa, estructurados por las particularidades que asumen las elites económicas en un momento histórico determinado.

\section{POLÍTICAS AGRARIAS: DESESTRUCTURACIÓN Y REESTRUCTURACIÓN EXCLUYENTE}

Para comprender las políticas estatales agrarias en Argentina, debe considerarse, tanto el ciclo de neoliberalización que comprendió la década de 1990 como el 
marco de alianzas de interés a través de las cuales en 2008 se dispuso el conflicto del entonces Gobierno Nacional con las patronales agropecuarias (véase, Gras y Hernández, 2016).

En la citada década, las capacidades administrativas de la entonces Secretaría de Agricultura registraron procesos de desposesión de instrumentos estatales: eliminación de organismos y atribuciones, concentración de actividades, privatización de instrumentos como warrants y mercados de futuro (Lattuada y Nogueira, 2011).

En cuanto al lapso abierto en 2008, este resulta relevante para comprender la dinámica de la gestión de la política agraria de 2015-2019, puesto que se trata de una alianza de intereses que habría propiciado -junto con otras alianzas establecidas desde y a través de las elites económicas- las condiciones para un nuevo ciclo de neoliberalización desde diciembre de 2015. En efecto, una vez en el gobierno, este vínculo fue retribuido a partir de una desregulación en distintas escalas: exención o reducción de impuestos a las exportaciones, supresión de cupos y cuotas de exportación, eliminación de control de precios, reducción de impuestos y tasas, así como desestructuración normativa y burocráticas (detallada en el ítem c del punteo expuesto más adelante).

De acuerdo a Canelo, Castellani y Gentile (2018, p. 125), los dos ministros que estuvieron a cargo de la cartera entre 2015 y 2018 eran los principales representantes de grupos de interés asociados al agronegocio: desde diciembre de 2015, Ricardo Buryaile, exvicepresidente de Confederaciones Rurales Argentinas (CRA), y desde noviembre de 2017, Luis Etchevehere, presidente de la Sociedad Rural Argentina (SRA). Según De Anchorena (2018, p. 198), el 52 \% (13 de un total de 25 cargos) del gabinete integrado por la primera gestión ministerial provenía de asociaciones de interés corporativo agroindustriales. La totalidad de los funcionarios poseían experiencia laboral en el sector privado, aunque nuevamente cerca de la mitad (44\%) detentaba una trayectoria privada pura. En el gabinete de Etchevehere sobresale la proporción de funcionarios que aporta una organización de interés en particular, la Aacrea, entidad con la cual el anterior ministro tenía una relación compleja, debido a su tradicional procedencia político-partidaria. Buryaile es dirigente de la Unión Cívica Radical, diputado nacional con experiencia en el aludido conflicto del agro y en el ámbito gremial (CRA). Estas credenciales determinarían su interés por seguir desplegando una carrera política antes que la exclusiva representación de intereses de la coalición gobernante en la cartera agroindustrial (Funcionario INTA, 2019b). Entre tanto, Etchevehere no parecería aspirar a una carrera política, aspecto que se evidencia en el desmonte de herramientas estratégicas ligadas a la pequeña producción a través de las cuales se hubieran podido atender parcialmente los 
efectos sociales de la crisis económica que acompaña casi ininterrumpidamente el mandato del presidente Macri8 (Funcionario INTA, 2019c).

En lo atinente a la política agraria, la administración iniciada en 2015:

- Desfinancia, desmonta y descontinúa iniciativas desarrolladas desde la Secretaría de Agricultura Familiar, el Programa Cambio Rural II fue una excepción (Funcionario del INTA, 2019a). Este accionar se manifiesta en el declive que puede observarse desde la gestión del primer secretario designado por el ministro Buryaile, con un perfil técnico, con conocimiento y trayectoria en la administración pública que se negó a ejecutar los despidos y recortes que se le exigía realizar, lo cual lo llevó a renunciar en octubre de 2016. Posteriormente, la secretaría acentúa su parálisis, pasando a ser conducida por sucesores que impulsaban el emprendedurismo (Funcionario INTA, 2019d), sinónimo actualizado del cuentapropismo. Por último, la gestión de Etchevehere se inicia en noviembre de 2017 con la Secretaría de Agricultura Familiar eliminada por parte de su antecesor en mayo de aquel año mediante el Decreto 302. La nueva gestión ministerial incrementó el hostigamiento y la cesantía ${ }^{9}$ de contratos dependientes de esta sección del entonces ministerio, a partir de la convicción de que los sujetos subalternos debían ser objeto de política asistencialista (Funcionario INTA, 2019b), dejando la intervención referida a la producción enfocada en los productores capitalizados, sobre todo en aquellos que evidencian mayor dinamismo productivo y tecnológico. El desmonte observado para el caso de la Secretaría de Agricultura Familiar forma parte de un contexto de desestructuración, del Ministerio de Agroindustria en particular y del Estado nacional en general. Se trata de un proceso observado en distintos meses del trienio 2016-2019, de forma prácticamente continuada. Específicamente, en el seno del Ministerio de Agroindustria, la disolución de la Secretaría de Agricultura Familiar antecedió a la eliminación, en marzo de 2018, de las subsecretarías de Alimentos y Bebidas, Bioindustria, Información y Estadística Pública, Lechería, Agricultura Familiar, Desarrollo Foresto-industrial, Control Comercial Agropecuario, Comunicación

8 Entre diciembre de 2015 y mayo de 2019, el peso argentino sufrió una depreciación cercana al 360 \%, el índice de precios al consumidor acumuló cerca de 200 \% de inflación, el PBI se redujo cerca de $3 \%$ mientras que el desempleo pasó de 5,9 a 10 \%. En el lapso 2015-2018, el Gobierno Nacional contrajo más deuda (en bonos nominados en moneda extranjera) que en la década de la convertibilidad peso-dólar (1991-2001) y cerca del doble que en el lapso 2003-2015 -71.000, 63.000 y 38.000 millones de dólares, respectivamente- (ITE, 2019).

9 En el bienio 2016-2017, el ministerio redujo su plantilla en 700 funcionarios, mientras que en abril de 2018 se desvinculó un $10 \%$ de los 3.500 empleados que desempeñaban funciones en la administración central del mismo, independientemente de los despidos y reducción de financiamiento realizados en organismos dependientes como el Senasa, el Instituto Nacional de Semillas, el Instituto Nacional de Vitivinicultura y el Instituto Nacional de Investigación y Desarrollo Pesquero (Página 12, 2018). 
Institucional y Coordinación Técnica y Administrativa. En ese momento, se reorganizó el ministerio (degradado a Secretaría en septiembre de aquel año) en las secretarías de Agricultura (conducida por un representante de Aacrea); Ganadería (dirigida por el Gerente General de la Cámara Argentina de Feedlot); Pesca y Acuicultura (a cargo de un abogado especialista en derecho pesquero), Mercados Agropecuarios (dirigida por un representante de un importante pool de siembra con operaciones en Argentina y Uruguay) y Coordinación Política (a cargo de un representante de la Confederación de Asociaciones Rurales de Buenos Aires y La Pampa -CARBAP-). La Subsecretaría de Desarrollo Territorial -conducida por un empresario ligado al turismo rural- absorbió a la de Agricultura Familiar (que se hallaba vacante desde enero de 2018). Además, se formó una nueva unidad: la Subsecretaría de Relaciones Agroindustriales Internacionales, la cual reportaba a la Secretaría de Mercados Agroindustriales -conducida por una funcionaria con amplios antecedentes en la gestión pública, que en octubre de 2018 pasó a ser Secretaria de Comercio Exterior del Ministerio de Producción y Trabajo- (El Economista, 2017; Valor Soja, 2018) ${ }^{10}$. Como puede observarse, la mayoría de estos cargos políticos fueron cubiertos por representantes empresarios o de organizaciones de interés. Asimismo, una significativa parte de los mismos provienen de la principal usina de ideas del PRO (partido del presidente Macri), la Fundación Pensar.

- Suprime la Unidad para el Cambio Rural-UCAR-, que nucleaba la provisión de infraestructura territorial. Se la ha intentado reemplazar infructuosamente por el mecanismo de las PPP.

- Incide en materia regulatoria con vistas a una reestructuración regresiva. Por un lado, facilita la extranjerización de la tierra y la privatización de propiedades fiscales mediante subastas a través del Decreto 820/16 que modificó la Ley 26737/2012, norma que estableció el régimen de protección al dominio nacional sobre la propiedad, posesión o tenencia de las tierras rurales. Asimismo, esta última definición contradice la creación de un banco de tierras que establece la Ley 27118 de "reparación histórica de la agricultura familiar para la construcción de una nueva ruralidad en Argentina" (De Anchorena, 2018, p. 195). Por otro, no reglamenta la recién citada ley. Por último, ha dispuesto la eliminación del

10 En agosto de 2019 el organigrama exhibía nuevas modificaciones: en su página web la Secretaría de Agricultura, Ganadería y Pesca dependiente del Ministerio de Producción y Trabajo reconocía solo tres subsecretarías (Agricultura, Ganadería y Pesca y Acuicultura) aunque las restantes tres se hallaban integradas en el organigrama de dicho ministerio. Asimismo, en el contexto de la campaña electoral y de su candidatura a la reelección, el presidente Macri se disponía a rejerarquizar la Secretaría de Agroindustria como ministerio. 
Registro Fiscal de Operaciones de Granos, del de Tierras Rurales Explotadas, del Sanitario de Productores Agropecuarios y del de Usuarios de Semillas.

- Interfiere en la autarquía del INTA. El mismo reclama su derecho a tratar sus demandas ante el ministro y ante el Congreso Nacional. Por señalar un caso, con ocasión del debate parlamentario para el presupuesto nacional 2019, las autoridades del INTA decidieron presentarse ante la Comisión de Presupuesto de la Cámara de Diputados para solicitar la partida adicional precitada de 400 millones de pesos, que servirían para financiar también proyectos y actividades de extensión ${ }^{11}$. Cabe considerar que esta definición desobedeció la postura ministerial y ha sido fustigada por las autoridades del mismo. Por otro, al suscribir el Gobierno Nacional un acuerdo stand by con el FMI, las principales determinaciones de política económica han sido delegadas a sus representantes, aspecto que complejiza más la intermediación con las autoridades políticas, empeñadas en auditar la eficiencia del gasto y en reducir el déficit fiscal a través del recorte presupuestario o de la restricción a su acceso en tiempo y forma (Funcionario INTA, 2019b).

En suma, al observar la definición de estas cuatro medidas, primó: a) el ideario de libertad de mercado para la obtención de precios alineados a las dinámicas internacionales, llegando incluso a fortalecer la perenne solicitud de sostener un tipo de cambio alto para poder licuar los costos de producción en moneda nacional (De Anchorena, 2018, p. 198) y a definir la desregulación de la obligatoriedad de liquidar las divisas producidas por la agroexportación; b) el estrechamiento de las posibilidades políticas debido a las restricciones fiscales asociadas al recetario impuesto por el citado acuerdo con el FMI, lo que hace colisionar las autarquías institucionales con la conducción gubernamental; c) el traspaso a la esfera estatal de un imaginario propio del empresariado agropecuario tradicional que asocia la relevancia de la producción primaria con el desarrollo nacional. Como se observa seguidamente, el cumplimiento de estas definiciones resultó factible por el propio origen de los funcionarios del Ministerio de Agroindustria de la Nación (De Anchorena, 2018).

\section{LA PUERTA GIRATORIA DE LAS USINAS DE PENSAMIENTO: COLONIZACIÓN Y DESMONTE DE LAS POLÍTICAS ESTATALES}

La orientación que signó la desestructuración y reestructuración de las políticas agrarias desplegadas en la administración iniciada en 2015 presenta antecedentes que

\footnotetext{
${ }^{11}$ El ajuste de los recursos estatales es una meta del gobierno de Mauricio Macri, ostensible desde el primer presupuesto nacional (2017) de su presidencia (véase, Ámbito Financiero, 2016).
} 
resultan útiles para comprender la profundidad de estas definiciones. Aacrea produjo información durante el conflicto de 2008. Esta participación política se articuló en instancias como la Fundación Pensar. Canelo, Castellani y Gentile (2018, p. 125) señalan que la colonización y captura de la definición estatal en materia agroindustrial trasciende la mera influencia en las políticas públicas mediante el cabildeo e implica la propia hechura de las mismas en clave de una reestructuración excluyente.

No obstante, resulta clave identificar cuál es la concepción de Aacrea. La base de la revolución tecnológica impulsada en el sector moderno del agro argentino (ligado al comercio exterior de commodities) por Aacrea se concibe desde el conocimiento empresarial en su faz agronómica y económica, especialmente en lo relativo a la productividad y la rentabilidad. La articulación entre tecnologías de gestión y producción y la dinámica estructural de un sector políticamente conservador encontró en la racionalidad científica una justificación clave para concebir una ideología del progreso y postularse como vanguardia en la economía nacional. Una racionalidad que respondiera a los argumentos esgrimidos por los sectores subalternos y sus organizaciones de interés, cuya idea central para explicar su subordinación reside en sindicar la concentración de la tierra como causa de su dificultad estructural. Desde este enfoque presente en Aacrea, el latifundio no sería contrario al progreso social, puesto que los empresarios buscarían una eticidad, centrada en la idea de que hacer más eficiente el uso y gestión de la tierra se dirige a servir a la sociedad (Balsa, citado por Gras y Hernández, 2016, p. 112). Una eticidad en la que la productividad se impone sobre miradas sistémicas y es evaluada a partir de análisis costo-beneficio centrados en el sector moderno del agro, fundamentalmente el pampeano. Asimismo, esta perspectiva se centra en la proporción minúscula que representan los productores de avanzada en la estructura agropecuaria nacional, tales como los adoptantes tempranos de tecnología ligada al agronegocio, que además suelen ser los asociados a Aacrea.

Por lo expuesto, el lugar que esta perspectiva asume al colonizar la orientación del Gobierno Nacional en materia de extensión rural del INTA es el de la experimentación agronómica especializada para asesores o productores de avanzada, competitivos en el escenario internacional (Funcionario INTA, 2019b). En contraposición, desde este enfoque, aquellos que registren dificultades para su reproducción debido a problemas de escala o tecnológicos no deberían ser sujetos de intervención estatal. Al ser consultado por la visión de funcionarios del elenco gubernamental en la gestión en el exministerio, un entrevistado señala: "la visión de ellos es trabajar para los empresarios, que de última el pequeño productor trabaje de empleado del empresario (...) lo tenían muy claro, lo están llevando adelante" (Funcionario INTA, 2019d). 
Esta claridad en torno a la orientación de la agenda agraria, no estuvo exenta del cambio del elenco de funcionarios. La propia conducción del INTA sufrió modificaciones con la salida del entonces ministro Buryaile, cuando el presidente del organismo -designado por el Gobierno Nacional iniciado en 2015- renunció a su conducción. En su reemplazo ocupó la presidencia Juan Balbín mientras que el vicepresidente siguió en su cargo. Durante la gestión de Etchevehere se desplazaron cuadros técnicos que habían llegado con el ministro saliente y se profundizó el alineamiento entre los sectores que respondían a los agroexportadores y al Gobierno Nacional (Funcionario INTA, 2019d). Este aspecto evidenció un desencuentro entre el Ministerio y el INTA, debido a que por su procedencia en la SRA solía desestimar un rol estatal que segmentaba su intervención en estructuras agrarias complejas y el valor que podía detentar la experiencia de intercambio con técnicos del INTA (Funcionario INTA, 2019b). Estos aspectos tuvieron su correlato institucional en el desmonte de la Secretaría de Agricultura Familiar.

Como se mencionó en relación con los cambios de elenco gubernamental en el propio Ministerio de Agroindustria, en 2017 se observa una profundización del proceso de captura del Estado. El mismo puede ser ejemplificado a partir de una denuncia judicial ${ }^{12}$ que tomó estado público en diciembre de 2018 en torno a una colusión de intereses en el seno del Consejo Directivo, órgano decisorio del INTA (Mesquida, 2018). El mismo es una instancia habitualmente valorada por los técnicos del Instituto (Funcionario del INTA, 2019a). Uno los cinco representantes por el sector privado, le corresponde a Aacrea (Decreto 287/1986). No obstante, la acusación se basaba en una incompatibilidad de cargos, esto debido a que las dos máximas autoridades, también eran socios de Aacrea (el actual presidente del INTA dirigió esa institución hasta 2013) y de CREA, que nuclea cerca de 2.000 empresas agropecuarias y desarrolla investigaciones técnicas para las mismas (CREA, 2019).

En concreto, la denuncia exponía que, mediante esta operatoria, se estarían limitando los servicios que brinda el INTA a los agentes agroindustriales de modo de prescindir de prestarlos y abonar a un escenario en el que se privatizara la oferta. Aacrea aparece como una asociación civil sin fines de lucro, que se halla integrada por empresarios agropecuarios reunidos en grupos para compartir experiencias y

12 La misma fue realizada ante la Procuración de Investigaciones Administrativas y la Oficina Anticorrupción y solicitaba que se investigara por administración fraudulenta y asociación ilícita al presidente y al vicepresidente del INTA, a un vocal y a un exvocal y al actual asesor rentado del Consejo Directivo del instituto. Este es el órgano de conducción (artículo 7, Ley 21.680) compuesto por diez consejeros, representantes en partes iguales por el sector público y por el privado. En 1977, la última dictadura cívico-militar (1976-1983) amplió el número de integrantes del Consejo Directivo en dos miembros, uno por las universidades y otro por los productores. Desde 1980, este último espacio es ocupado por un representante de Aacrea (Gargano, 2016, p. 36). 
conocimientos. Sin embargo, los asesores técnicos de esta organización perciben una remuneración por los servicios de investigación y extensión brindados a los productores, que el INTA presta de forma gratuita (Mesquida, 2018). Este intento de privatización de la extensión puede estar asociada al hecho que la dirigencia de Aacrea promueve la adopción de tecnología aunque también persigue una dirección política del sector agropecuario, lo cual implica una dimensión transformadora que escamotea una restauración de su posición de clase (Dosi, 1982 y Gramsci, citados por Gras y Hernández, 2016, p. 112). Al analizar la dependencia institucional del INTA de la Secretaría de Agroindustria y tal como se señaló más arriba, la denuncia refiere que dos funcionarios del exministerio también y el presidente del Senasa responden al Aacrea, con lo cual resulta a priori incierto que estos velen para evitar los procesos de captura en el INTA.

La situación apuntada en el párrafo anterior resulta coherente con las formas de proceder de funcionarios sin experiencia en la gestión pública. Este aspecto alimentaría una tensión interna en el seno de Aacrea, debido a que algunos dirigentes poseen una valoración negativa de la administración estatal, en parte fundada en prejuicios sedimentados transgeneracionalmente en torno a la misma y que se sublima en frases como "no es que queremos hacer política, queremos hacer otra cosa" (Funcionario INTA, 2019c). Mientras tanto, otros dirigentes de esta organización intentan aprender en un contexto en el que poseen altas responsabilidades sin una expertise previa que es propia de los dirigentes de partidos políticos tradicionales (por caso, del Partido Justicialista o de la Unión Cívica Radical). Esta tensión, incluso, se manifiesta en la trayectoria del Jefe de Gabinete del Exministerio de Agroindustria de Etchevehere, que en 2017 pasó de Aacrea a la SRA y en las diferencias entre ambos y el resto de los funcionarios de esta entidad -que hegemoniza la orientación política en dicha cartera-(Funcionario INTA, 2019b).

No obstante, el ritmo y las rutinas propias de la gestión pública, cristalizadas a lo largo de décadas y que trascienden los cambios de elencos gubernamentales, suelen colisionar con las formas de proceder de funcionarios que provienen de la gestión privada. Por caso, cabe señalar la incomprensión en torno a la obligatoriedad de las rendiciones de gastos corrientes, la generación de relaciones laborales basadas en el hostigamiento, la dificultad por advertir que en cada dependencia estatal se desempeñan personas con tendencias políticas disímiles y hasta contrapuestas y que no necesariamente responden de forma orgánica a dirigentes o partidos opositores, etc. (Funcionario INTA, 2019c). Este desconocimiento de la administración y de las características de las burocracias a través de las cuales los funcionarios pretenden operar, conspiró, en términos temporales y de eficacia, contra los resultados de gestión (Funcionario INTA, 2019d). 
El cuadro arriba indicado se vería agravado por la complejización que sufre el aparato estatal debido a la eliminación de ministerios y al monitoreo del cual es objeto la administración nacional por parte del FMI. Por un lado, la degradación a Secretaría, implica que su ubicación resultante es de intermediación entre el Ministerio de Producción y Trabajo - de quien depende ahora como Secretaría- y el INTA (Funcionario INTA, 2019b). Esta definición puede considerarse una renuncia a políticas activas y segmentadas para el sector (Funcionario del INTA, 2019a). Por otro, el ahora exministerio ha digitalizado procesos de control para el seguimiento estadístico de distintas producciones agroindustriales, mientras ha relegado en manos del Ministerio de Producción y Trabajo la Secretaría de Comercio Exterior (Funcionario INTA, 2019b). La digitalización aludida se inspira en una lógica de modernización tecnocrática que suele ligar burocracia con traba para la realización económica. Asimismo, dicha lógica asume a la gestión estatal -con sus rituales y tiempos- como una carga para la realización tecnocrática, que desde sus funcionarios se erige como una misión pedagógica mediada por el management en la que se viene a enseñar, no a interactuar ni a aprender con la burocracia (Muller, 2010, p. 172). En tal sentido, se observa una contradicción: mientras se asocia modernizar a la agilización de trámites vía digitalización de procesos administrativos, se alargan los canales institucionales - con su impacto en la administración de los plazos- para resolver problemas de gestión, sobre todo, el otorgamiento de partidas presupuestarias en tiempo y forma.

Por último, al observar el Plan Estratégico Institucional 2015-2030 y la cartera de programas y proyectos 2018-2022 del INTA, se tenderían a desplazar enfoques territoriales (usualmente asociados a propuestas integrales e interdisciplinarias) por otros clásicos, tales como los de cadenas de valor y propios de la época. Por caso, los proyectos regionales con enfoque territorial pasan a llamarse Plataformas de Innovación Territorial, modificación resumida como concepto-slogan acorde con la orientación e influencia ideológica de Aacrea y desmovilizante para los técnicos de terreno que cumplían una labor de orientación productiva y contención social de los grupos vulnerables. En definitiva, la modificación de los conceptos-slogan como enfoque territorial e innovación territorial, podría exponer desavenencias históricas entre las actividades de extensión y de investigación en el seno del INTA, cuya centralidad varía de acuerdo a la orientación ideológica que predomina en su conducción (Funcionario INTA, 2019 d).

En definitiva, se trata de una colonización de la agenda institucional evidente, en palabras de un informante calificado (Funcionario del INTA, 2019a):

Aacrea tiene un fuerte manejo sobre el INTA, cada vez más (...) tanto en los consejos locales asesores [integrados por funcionarios técnicos, productores y 
representantes de los organismos provinciales], en el Consejo Directivo, dentro del Exministerio de Agroindustria en el Senasa, en la Jefatura de Gabinete del Exministerio, en la Subsecretaría de Agricultura (...) claramente hay colonización, pero es lógico que así sea porque responde a la cuestión ideológica del gobierno.

Este proceso no está exento de tensiones en torno al rol y a los objetivos que debe cumplir el INTA (Funcionario INTA, 2019b), aspecto que encierra desavenencias entre distintas cosmovisiones de la producción agropecuaria, sus sujetos y las demandas canalizadas institucionalmente (Funcionario INTA, 2019c).

\section{CONCLUSIONES}

En el recorrido aquí planteado, durante la gestión 2015-2019 que impulsó el tercer ciclo de neoliberalización, gobernar las políticas agrarias ha implicado la construcción desde asociaciones de interés de diversas modalidades de acción, dirigidas no solo a actuar sobre las posibilidades de acción de los otros, tal como plantea Foucault (2001), sino que también a reorientar las políticas agrarias para reforzar el modelo de agronegocios de un selecto grupo de productores y adoptantes de tecnología.

En la Argentina que se pretendía agroexportadora, Juan Bautista Alberdi, un prominente político de pensamiento liberal y autor intelectual de la Constitución Nacional de 1853, reflexionaba sobre las formas que tendría la organización estatal. Alberdi consideraba (1879, pp. 6 y 11) que:

Gobernar es poblar en el sentido que poblar es educar, mejorar, civilizar, enriquecer y engrandecer espontánea y rápidamente (...) Poblar es enriquecer cuando se puebla con gente inteligente en la industria y habituada al trabajo que produce y enriquece. (...) ¿Cuál es la Constitución que mejor conviene al desierto? La que sirve para hacerlo desaparecer; la que sirve para hacer que el desierto deje de serlo en el menor tiempo posible, y se convierta en país poblado.

Las argumentaciones de Alberdi, influidas por las discusiones de la modernidad, parecieran estar presentes en las orientaciones que han adquirido las políticas agrarias, fundamentalmente a partir de 2015. Si ya no se trata de poblar, ahora resulta más pertinente pensar en la colonización y captura. Más que del pretendido desierto del siglo XIX, ahora se trata de la construcción de mecanismos de soporte a la neoliberalización, de captura en la orientación de las políticas agrarias por parte de las elites económicas y sus organizaciones de interés, mediante la desestructuración y reestructuración excluyente.

Sin embargo, la captura del Estado puede ser fugaz y es un argumento en contra de una perspectiva de atrincheramiento estricto o de capitalismo de amigos donde las principales empresas dominantes mantienen (o fugan al exterior) sus recursos a través de la permanente influencia política. Como señalan Ross Schnei- 
der y Karcher (2012, p. 21), usualmente el alto volumen de negocios entre las elites económicas contradice también al argumento de atrincheramiento. Por lo tanto, la colonización de áreas estatales por parte de organizaciones de interés ligadas a la reestructuración excluyente que promueven dichas elites puede ser un capítulo más del devenir histórico de las alianzas de interés en las que las posiciones son dinámicas y cambiantes.

\section{BIBLIOGRAFÍA}

Alberdi, Juan Bautista (1879). Bases y puntos de partida para la organización política de la República de Argentina. Buenos Aires: Colihue, 416 p.

Ámbito Financiero (2016). Macri quiere alimentar al mundo pero le recorta fondos al INTA, Argentina, p. 12.

Armengol, Germán (2015). El conflicto del campo de 2008: consolidación del modelo sectorial de agronegocios y crisis de hegemonía. Tesis para optar al título de Licenciado en Sociología. Licenciatura en Sociología, Universidad Nacional de la Plata, Argentina, 67 p.

Basualdo, Eduardo (2011). Sistema político y modelo de acumulación. Tres ensayos sobre la Argentina actual. Buenos Aires: Atuel, 224 p.

Cao, Horacio; Laguado Duca, Arturo y Rey, Maximiliano (2018). El homo corporativo: las élites estatales en el neoliberalismo tardío. En: García Delgado, Daniel; Ruiz del Ferrier, Cristina y De Anchorena, Beatriz (Comps.), Élites y captura del Estado. Control y regulación en el neoliberalismo tardío. Buenos Aires: Flacso, p. 137-156.

Canelo, Paula; Castellani, Ana y Gentile, Julia (2018). Articulación entre élites económicas y élites políticas en el gabinete nacional de Mauricio Macri (2015-2018). En: García Delgado, Daniel; Ruiz del Ferrier, Cristina y De Anchorena, Beatriz (Comps.), Élites y captura del Estado. Control y regulación en el neoliberalismo tardío. Buenos Aires: Flacso, p. 117-136.

CREA -Consorcio Regional de Experimentación Agrícola (2019). Qué es CREA, Argentina, 1 p.

De Anchorena, Beatriz (2018). Poder empresario y políticas públicas. La captura de las políticas agropecuarias. (2015-2018). En: García Delgado, Daniel; Ruiz del Ferrier, Cristina y De Anchorena, Beatriz (Comps.), Élites y captura del Estado. Control y regulación en el neoliberalismo tardío. Buenos Aires: Flacso, p. 183-208.

El Economista (2017). Anuncian que habrá cambios en Agroindustria, Argentina, 1 p.

Exfuncionario Ministerio de Agricultura, Ganadería y Pesca de la Nación (2019). Ingeniero Agrónomo, Coordinación de Extensión y Cambio Rural. Buenos Aires, 12 de marzo de 2019.

Fernández, Víctor (2016). Desde el laboratorio neodesarrollista a la resurgencia neoliberal. Una revisión creativa del "doble movimiento" polanyiano en América Latina. En: Revista Estado y Políticas Públicas, n. ${ }^{\circ}$, p. 21 47.

Foucault, Michel (2001). El sujeto y el poder. En: Dreyfus, Hubert y Rabinow, Paul (Eds.), Michel Foucault: más allá del estructuralismo y la hermenéutica. Buenos Aires: Nueva Visión, p. 241-259. 
Funcionario INTA (2019a). Especialista en comunicación rural, asistente de sistemas de información, comunicación y calidad, Dirección Nacional. Buenos Aires, 12 de febrero de 2019.

Funcionario INTA (2019b). Ingeniero agrónomo, Dirección Nacional. Buenos Aires, 19 de febrero de 2019.

Funcionario INTA (2019c). Delegado gremial, Coordinación Nacional de Transferencia y Extensión. Buenos Aires, 1 de marzo de 2019.

Funcionario INTA (2019d). Politóloga, Instituto de Investigación en Prospectiva y Políticas Públicas. Buenos Aires, 22 de marzo de 2019.

Gargano, Cecilia (2015). Peronismo, agro y tecnología agropecuaria. La reconfiguración del INTA (1973-1976). En: Saber y Tiempo. Revista de Historia de la Ciencia, vol. 1, n. ${ }^{\circ}$ 1, p. 32-58.

García Delgado, Daniel (2017). Modernización y reforma del Estado en el neoliberalismo tardío: hacia el Estado presocial. En: García Delgado, Daniel y Gradin, Agustina (Comps.). El neoliberalismo tardío. Teoría y Praxis. Buenos Aires: Flacso, p. 93-108.

Gras, Carla y Hernández, Valeria (2016). Hegemonía, innovación tecnológica e identidades empresariales: 50 años de revoluciones agrícolas en Argentina. En: Estudios Críticos del Desarrollo, vol. 6, n. ${ }^{\circ}$ 11, p. 107-128.

Infocampo (2018). Escándalo en Agroindustria: denuncian que Aacrea está "vaciando" al INTA para privatizarlo, Argentina, p. 1.

ITE -Instituto de Trabajo y Economía (2019). Observatorio de la deuda: balance 2018. Recuperado de http://itegaweb.org/wp-content/uploads/2019/01/Observatorio-de-la-Deuda-Balance-2018.pdf

La Nación (2017a). El Estado se investiga a sí mismo: abrieron 4.500 sumarios a funcionarios, Argentina, p. 16.

La Nación (2017b). Según un relevamiento, desde que asumió Macri aumentó en un 25 \% la estructura del Estado, Argentina, p. 9.

Ghibaudi, Javier; Lavarello, Pablo y García, Ariel (2018). Autonomía y enraizamientos en la búsqueda del cambio estructural. Un análisis a partir de la política industrial en Argentina y Brasil a principios del siglo XXI. En: Ejes de Economía y Sociedad, vol. 2, n. ${ }^{\circ}$ 3, p. 14-39.

Lattuada, Mario y Nogueira, María Elena (2011). Capacidades estatales y políticas públicas. Una propuesta para el abordaje de las políticas agropecuarias en la Argentina contemporánea (1991-2011). En: Estudios Rurales, vol. 1, n. ${ }^{\circ}$ 1, p. 30-54.

Maillet, Antoine (2013). La construcción política de los mercados. Variedades de neoliberalismo en el Chile posdictadura (1990-2010). Tesis para optar al título de Doctora en Ciencia Política. Doctorado en Ciencia Política, Pontificia Universidad Católica de Chile y Sciences Po París, Santiago de Chile, 202 p.

Muller, Pierre (2010). Las políticas públicas. Bogotá: Universidad Externado de Colombia, 200 p.

Página 12 (2018). En Agroindustria pasaron con la sembradora, Argentina, p. 10. 
RAE -Real Academia Española (2019). Definición de gobierno. Recuperado de https://dle.rae. es/?id=JHWWluC

Presidencia de la República de Argentina (1956). Decreto-Ley 21.680 de diciembre 4 de 1956. Créase el Instituto Nacional de Tecnología Agropecuaria, 7 p.

Presidencia de la República de Argentina (2017). Decreto 302 de abril 28 de 2017. Modificatorias relativas al Ministerio de Agroindustria de la Nación, 40 p.

Ross Schneider, Ben y Karcher, Sebastián (2012). La política de las empresas en Latinoamérica: investigando sus estructuras, preferencias e influencia. En: Apuntes. Revista de Ciencias Sociales, vol. 39, n. ${ }^{\circ}$ 70, p. 7-28. Doi: 10.21678/apuntes.70.644

Romero Alvarado, Luz (2015). regulación económica: una aproximación al marco teórico y conceptual. En: Derecho y Realidad, vol. 13, n. ${ }^{\circ} 25$, p. 43-62.

Valor Soja (2018). Llegó la reingeniería organizacional al Ministerio de Agroindustria: eliminaron a la Secretaría de Lechería, Argentina, p. 3.

Varesi, Gastón (2016). Neodesarrollismo y kirchnerismo. Aportes para un análisis conjunto del modelo de acumulación y la hegemonía en Argentina 2002-2008. En: Cuadernos del Cendes, vol. 33, n. ${ }^{\circ}$ 92, p. 23-57.

Visión Liberal (2018). El gobierno da "luz verde" a la reducción de ministerios a través de una ley, Argentina, p. 1. 